\section{Harnessing usability to choose appropriate incontinence care products}

$\begin{array}{ll}\text { ladder problems affect more than } & \text { Usability is defined as the extent } \\ 200 \text { million people worldwide } & \text { to which a product can be used to }\end{array}$ 3200 million people worldwide Organization. Bowel problems are also not uncommon and it is thought that $10 \%$ of adults may experience bowe major symptom ${ }^{1}$ The NHS esting that between 3 and 6 million people in the UK have some degree of urinay incontinence ${ }^{2}$ Urinary incontinence is costly to society and healthcare services, both financially and in term of physical and mental health. Due to the pressures that incontinence
places on caregivers and healthcare systems, there is a need to match

patients and caregivers with

appropriate, effective absorbing incontinence products that they can change easily, such as for disabled patients in a homecare environment and for professional caregivers in

Historically, evaluation of incontinence care products has focused on absorption capacity, with little environmental factors. The needs of users and caregivers in evaluating absorbing incontinence care products have been increasingly highlighted in more recent guidelines, but to date without specific advice on methods targeting these needs.

Due to their expertise in metrology, the study of measurements, Professor Leslie Pendrill and his team at RISE Research Institutes of Sweden AB have been involved in the development of a usability score in conjunction with Essity $A B$. chieve the user's goals and needs effectively and efficiently. Usability is an important concept for helping cand when choosing ind be considered products. Usability scores are already applied to many other product types and we believe they should be encouraged for healthcare and hygien products as well. In addition to practica applications of a usability score, recent surveys have also shown that patients have a better quality of life if they are informed and supported in their choice

THE STUDY

This research carried out by Professor Pendrill and colleagues epresents the first scientific study of absorbent

It was loosely informed by a previous tudy of continence care whic interactions between a product user, the product and the task. This study, along with existing standards and guidelines, highlighted the variety of factors which need to be considered when choosing the best products for individuals with urinary incontinence. Individual assessment is crucial as a product needs to be specifically matched to each care and user; a 'one size fits all' approach is not suitable.

The aim of their previous study was to develop and test a new method whability of a used to measure the care products. More importantly, the

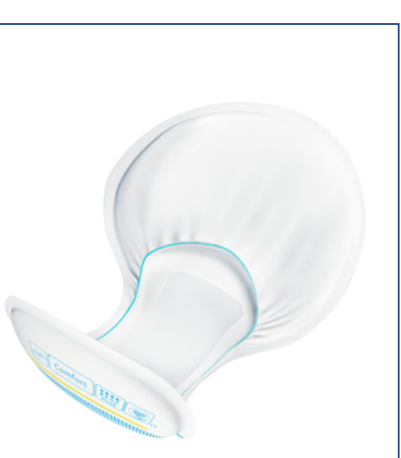

ody - worn Pads with Mesh Brie

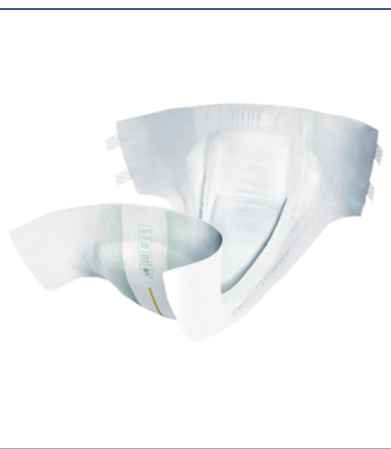

All-in -One Brief

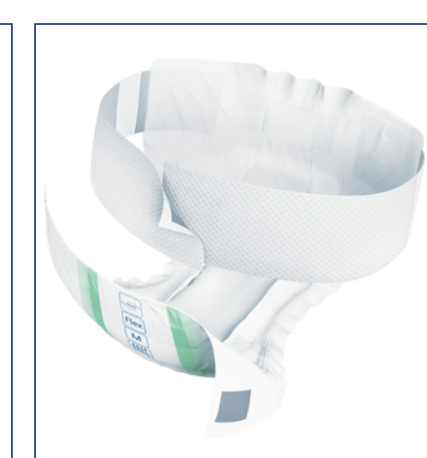

Belted Brie

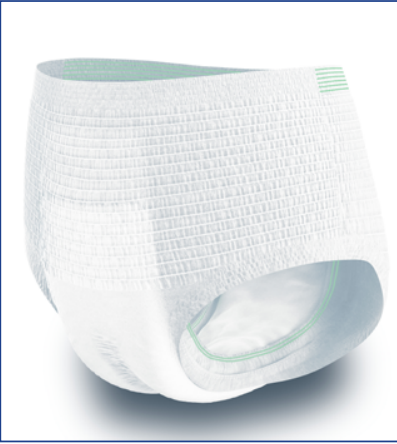

Pull - up Pants team wanted to do this by investigating usability from a caregiver's perspective. The final part of the study aimed to determine whether this newly defined measure of usability could be used to

The study ultimately applies a new method to guide product selection from one product to another. Both product developers and end users were involved in the design of the new usability method, meaning it is specifically tailored to suit the realworld needs of caregivers

\section{STUDY DESIGN}

was the aim of the research team at Essity AB and RISE to develop a valid and reliable method to assess usability of different types of incontinence product, to compare the different product types, use in certain healthcare settings.

Once the method had been designed, it was evaluated for its levels of

. evaluations using a range of diffe methods. These included the use of cameras to monitor task performance, test moderators to time product changes and postures, pre-defined scores to measure product fit and questionnaires to assess satisfaction scores. The usability score was based on four scores; effectiveness, or how well the product fitted the use caregiver time, caregiver workload nd caregiver satisfaction.

Effectiveness was assessed by visual inpection by a tester after each product whether the product was fitted as intended by the caregiver and whether the product provided sufficient coverage for the user. Efficiency was measured as hange. This covered the a product from when the caregiver first received the product and applied protective clothing to the end of the process. Task workload was also measured and was defined as a combination of the time and effort required by the caregiver to complete the change, for example the pressure on the spine if a caregiver is required to reposition a patient. Finally, satisfaction was assessed using a self-reported

aire provided to the caregiver.

The products tested included belted briefs, pull-up pants, all-in-one briefs

with side fastenings and body-worn pads held in place with a mesh brief.

STUDY FINDINGS The study used a person-centred approach which aimed to generate making and producte for decision The findings of the study showed that the usability score developed by Professor Pendrill and colleagues was able to discriminate between usability of different product types.

Data analysis showed that products with a high usability score were in terms of changing and workload for caregivers. More pants were more effective than all-in-

Urinary incontinence is costly to society and healthcare services, both financially and in terms of physical and mental health.

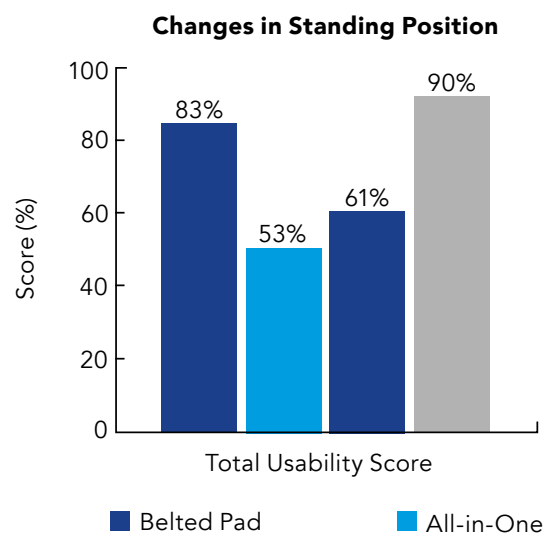

The usability study showed hiat belted and pants products hare
scores compared to an all-in-one product or pad with fixation.
Changes in Lying

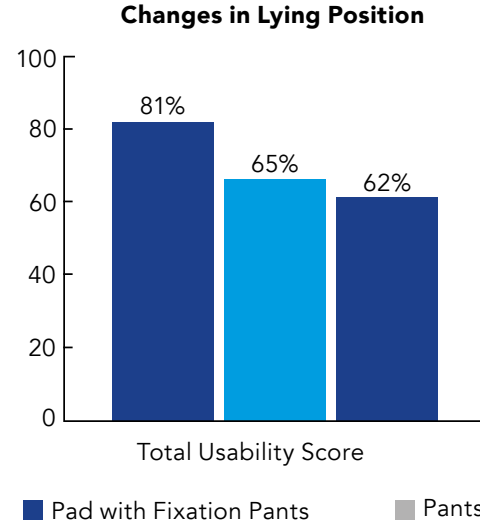




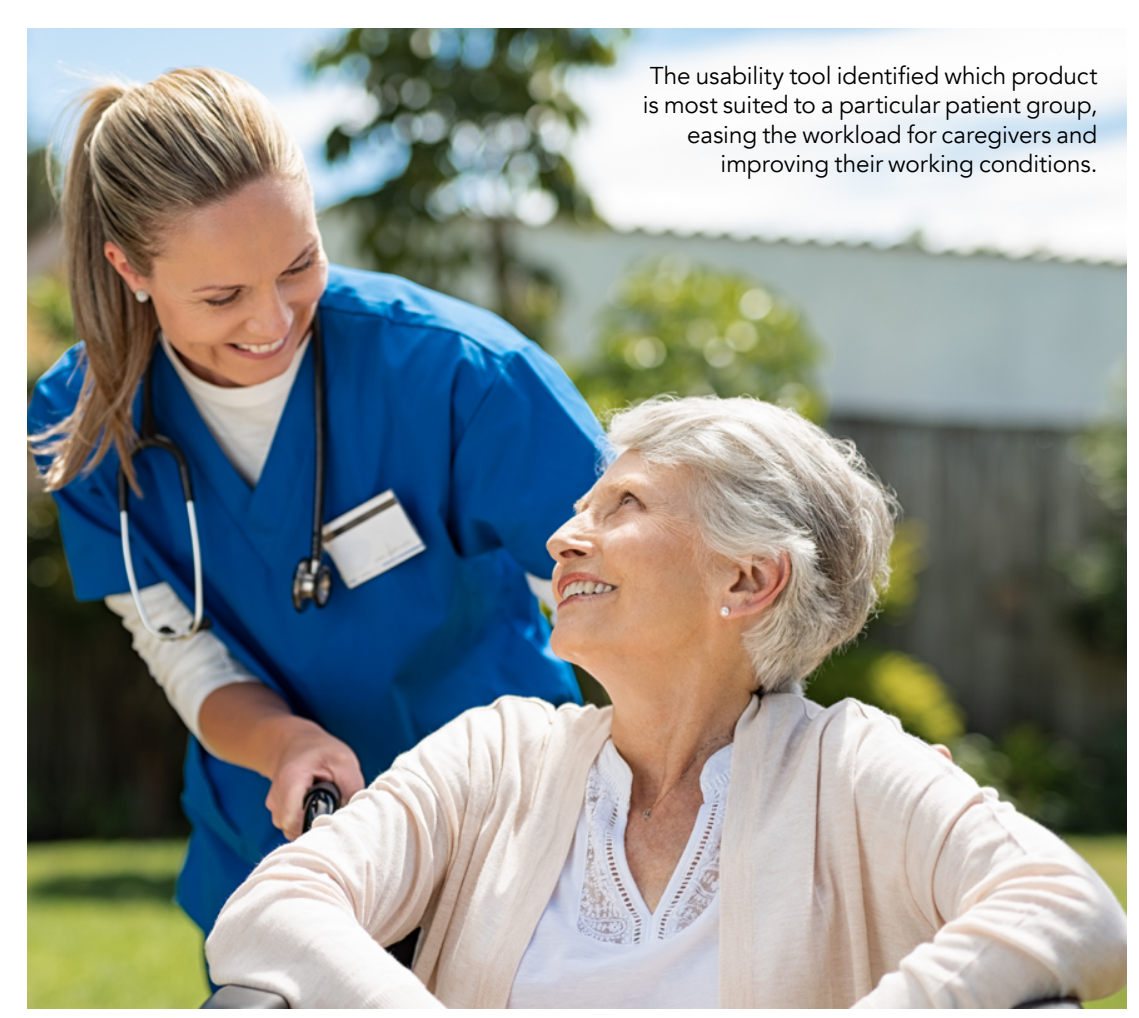

Usability is defined as the extent to which a product can be used to achieve the user's goals effectively and efficiently. one briefs and body-worn pads held in place with a mesh brief.

When the products themselves were compared, those which performed best when changed in the standing Flex (belted briefs). TENA Flex was also ranked highly for its satisfaction score when changes were made when the patient was lying down. This is an important factor to consider as product users will vary in their mobilty

\section{Scenario 1 - resident annual calculation}

\section{Basic conditions}

standing* (sec)

Changes/day (local data)

Number of backbends

Time in backbend* ${ }^{\star}$ sec)

Carer satisfaction*

Usailitions based on usability study

Annual number of changes

Number of backbends

Time in backbend (hrs)

Total Time Changes (hrs)

Cost for changes

Carer satisfaction

\begin{tabular}{|c|c|c|c|}
\hline FLEX & PANTS & $\mathrm{AlO}$ & $2 \mathrm{P}$ \\
\hline 73,1 & 59,6 & 94,6 & 86,4 \\
\hline 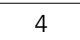 & 1 & 4 & 4 \\
\hline$f 8,75$ & $f 8,75$ & $f 8,75$ & f8,75 \\
\hline 5 & 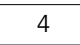 & 8 & 6,5 \\
\hline 36,5 & 34,9 & 57,1 & 59,5 \\
\hline 0,82 & 0,86 & 0,50 & 0,58 \\
\hline
\end{tabular}

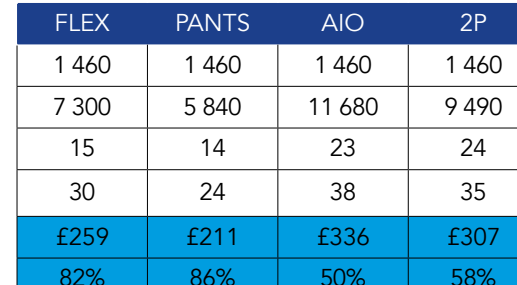

The Usability Value Calculator is a tool to calculate the usability impact in care facilities. changed standing up, then belted

\section{CONCLUSIONS}

The work carried out by Professor Pendril and the research team demonstrates that usability, a concept familiar from other product categories (such as computer incontinence care. Furthermore, usability can be captured in a standardised way so that different products can be benchmarked objectively.

The results of the study provide a tool to determine which incontinence product can be most easily changed in specific situation. Using products most suited to a particular setting or patient group means that caregivers are able Easing the workload for caregivers wil mprove their working conditions and allow them to use their time and skills more effectively.

The research team has succeeded in producing a method to measure absorbing incontinence care product change in terms of the three main components of usability: efficiency effectiveness and satisfaction. This methodology supports evaluation and interpretation of usability for decision making and makes product grading possible, in addition to enabling comparison of usability for product

The authors of the study identify some mitations, paving the way for future investigations. For example, the resting is suggest that additional help confirm the usability tool. The current study collected data from a simulated care environment, however testing of the concept in real-world care environments is still required in order to add weight to the newly designed usability score for absorbent incontinence products.

Overall, the concept of usability for selecting incontinence care products is one that could be applied to many settings, from private healthcare and has the potentia to and has the potential to change

\section{Behind the Research}

\section{Leslie Pendrill}

E: lesliependrill@gmail.com T: $+46767885444 \quad$ W: https://www.essity.com/

\section{Research Objectives}

The research team is dedicated to improving well-being through leading hygiene and health solutions.

\section{Detail}

Leslie Pendrill

Storskiftesvägen 11

43341 Partille

Bio

Professor Pendrill, formally R \& D Director at the Swedish National Metrology Institute (now RISE), has chaired several international metrological organisations as well as developing new quality-assured measurement methods. A current theme is Man as a Measurement Instrument: for example, measuring perception, cognition, etc. He has recently authored a book about Quality-assured Measurement (Springer Nature).

\section{Funding} the products for the study.

Collaborators

The authors would like to thank Ragne Emardson, Petra Sommarlund and Anders Trana at RISE Research Institutes Scandinfo Marketing Research AB for provision of the trial facilities, recruitm of participants and performing of tests.

\section{References}

1. World Health Organization Calls First International 1 Consult tation on Incontinence. Ples Resder and Bowel UK website accessed July 2019.

2. Irwin, D., Milsom, I. et al. Impact of overactive bladder symptoms on employment, social interactions and
emotional wellbeing in six European countries. Br. J. Urol. Int. 2005; 97, 96-100

3. Rice, S. K., Pendrill, L., Petersson, N., Nordlinder, J., Farbrot, A. (2018). Rationale and Design of a Novel Method to Assess the Usability of Body-Worn Absorben Ostomy Continence Nurs., 45(5):456-464. doi: 10.10971 WON.00000000000000462

\section{Personal Response}

Do you have plans for further studies to further validate the usability tool in real-world settings? II At the moment there are no immediate plants to validate the usability tool in real-word settings but
there has been some interest among care providers to initiate this. The key to a successful validation is to find a care provider that has the time and resources to participate and that is a challenge as the care 